\title{
PRESERVATION OF VISUAL FUNCTION IN PAPILLOEDEMA* $†$ OBSERVED FOR 3 TO 6 YEARS IN CASES OF BENIGN INTRACRANIAL HYPERTENSION
}

BY

\section{M. RABINOWICZ $\ddagger$ I. BEN-SIRA, AND H. ZAUBERMAN}

From the Department of Ophthalmology, Hadassah University Hospital, Jerusalem, Israel

PAPILLOEDEMA associated with a space-occupying lesion and raised intracranial pressure is known to lead to the development of optic atrophy within a few months unless the intracranial pressure is relieved with the minimum of delay (Huber, 1961). The atrophic changes are often accompanied by marked impairment of function as evinced by diminished visual acuity and by defects of visual field.

However, visual impairment following the development of atrophy associated with papilloedema in cases of increased intracranial pressure is infrequent in the condition known as benign intracranial hypertension. Many cases of short duration have been described, with a minimal loss of visual function over a period of up to 12 months, and a careful survey of the literature reveals a few cases in which papilloedema appears to have persisted for longer, in rare cases for as long as 2 years (Ford and Murphy, 1939; Giller and Cogan, 1952; Foley, 1955; Marr and Chambers, 1961). Most of these showed no ultimate functional loss. Cases with more severe eventual impairment do occur but are very rare (Dandy, 1937; Cross, 1948; Bradshaw, 1956; Smith, 1958). The fact that we were unable to find reports in the literature of papilloedema persisting in this condition for longer than 2 years prompted the present study.

A series of patients is presented who suffered from benign intracranial hypertension for between 3 and 6 years and whose visual function remained unimpaired, or was but mildly affected.

\section{Case Reports}

Thirty patients diagnosed as suffering from benign intracranial hypertension have been examined at the Hadassah University Hospital, Jerusalem, during the period 1951 to 1966 . Of these, 22 cases had been diagnosed for a period of less than 2 years and have been excluded from the present study. The remaining eight patients, in whom the disease had been present for between 3 and 6 years, are considered below.

* Received for publication January 26, 1967.

+ Address for reprints: Moorfields Eye Hospital, High Holborn, London, W.C.1

‡ On leave from Moorfields Eye Hospital, High Holborn, London, England. 
Case 1, a 24-year-old man, was investigated in the Neurological department in 1955 on account of headaches and vomiting of recent onset.

Examination.-Nothing abnormal was observed. The visual acuity was $6 / 6$ in both eyes, and symmetrical papilloedema of 4 dioptres, with haemorrhages and exudates around both discs, was present. The visual fields showed only enlarged blind spots. Lumbar puncture showed a pressure of $500 \mathrm{~mm}$. $\mathrm{H}_{2} \mathrm{O}$. The cerebrospinal fluid was normal. Electro-encephalography and skull $x$ rays were normal. Full air studies showed normal ventricles, and angiography added no further information.

Diagnosis.-In view of the clinical and radiological findings, a diagnosis of benign intracranial hypertension was made. Similar criteria were used in all cases described.

Treatment.-Repeated lumbar punctures, which gave pressures varying between 160 and $500 \mathrm{~mm} . \mathrm{H}_{2} \mathrm{O}$, and a course of Diamox, made little impression on the hypertension. In view of the papilloedema, a right subtemporal decompression was carried out 2 months after the onset of symptoms. Subsequently, lumbar puncture pressures ranged from 240 to $300 \mathrm{~mm}$. $\mathrm{H}_{2} \mathrm{O}$.

Progress.-Although the haemorrhages and exudates in the fundi gradually disappeared, papilloedema of some 2 dioptres persisted at 3-monthly examinations during the follow-up period 1955 to 1960 . The patient remained quite well apart from the periodic recurrence of his original symptoms. There was neither deterioration of visual acuity nor alteration of visual field.

In 1961, when the patient was last seen, 6 years after the initial diagnosis, the papilloedema had receded, leaving a little blurring of the disc margins and moderate pallor of the disc itself, but with no constriction of the retinal vessels. There was no alteration in the visual findings previously noted.

The visual field examinations were all carried out with a Goldmann perimeter, using the $2 / 1$ and $4 / 1$ targets. The same detailed field examination was carried out in the subsequent cases to be reported.

Case 2, a 41-year-old woman, presented with blurring of vision of gradual onset.

Examination.-There was no physical abnormality. Papilloedema of 3 dioptres, with discrete haemorrhages and exudates surrounding the discs, was noted. The visual acuity was $6 / 6$ in both eyes. The blind spots were enlarged with no other field abnormality. A single lumbar puncture recorded a pressure of $200 \mathrm{~mm} . \mathrm{H}_{2} \mathrm{O}$, the cerebrospinal fluid being normal on analysis.

Diagnosis.-A probable diagnosis of benign intracranial hypertension was made after normal angiography and air studies.

Progress.-The patient attended at 3-monthly intervals from 1961 to 1964, during which time the haemorrhages and exudates gradually disappeared, but bilateral papilloedema of 2 to 3 dioptres persisted.

In 1963, lumbar puncture gave a pressure reading of $350 \mathrm{~mm}$. $\mathrm{H}_{2} \mathrm{O}$ despite a course of Diamox, thus confirming the original tentative diagnosis. The visual acuity and fields both remained unchanged throughout the 3-year follow-up period.

Case 3, a 49-year-old female, presented early in 1962 with slight blurring of vision.

Examination.-Nothing abnormal was observed. Papilloedema of 1 dioptre and 3 dioptres was present in the right and left eyes respectively, with haemorrhages and exudates of mild degree around both disc margins. The visual acuity was $6 / 6$ in both eyes. Bilateral enlargement of the blind spots was noted, more marked on the right side. Lumbar puncture gave a pressure reading of $260 \mathrm{~mm} . \mathrm{H}_{2} \mathrm{O}$ with normal cerebrospinal fluid. Cerebral angiography and air studies were normal.

Progress.-A 3-monthly follow-up from 1962 to 1966 showed persistant papilloedema of 1 to 2 dioptres in each eye. In 1965, over 3 years after the onset of symptoms, a slight peripheral constriction of the right inferior nasal field was noted, but this has not progressed. The visual acuity remains unchanged.

Case 4, a 30-year-old man, had a mild episode of meningo-encephalitis in 1963 at which time mild blurring of the disc margins was noted. His condition cleared within a week. He presented again 4 months later with headaches, nausea, and blurring of vision.

Examination.-No abnormality was observed. The visual acuity was $6 / 6$ in both eyes. Bilateral papilloedema of 4 to 5 dioptres was present, with haemorrhages around the disc margins. Examination of the fields of vision revealed a slight inferior nasal constriction on both sides, with enlarged blind spots. The 
cerebrospinal fluid revealed no abnormality. Lumbar puncture repeated at an interval of one week gave pressure levels of 180 and $280 \mathrm{~mm} . \mathrm{H}_{2} \mathrm{O}$. Cerebral angiography revealed a severely-constricted superior sagittal sinus. Ventriculography showed small ventricles.

Progress.-He was given Diamox for several months, but this was discontinued as it appeared to be ineffective in controlling the hypertension. Between 1964 and 1966 the papilloedema remained at about 2 dioptres and the visual fields have returned almost to normal apart from persistently-enlarged blind spots. The patient's general condition is good and his visual acuity remains unaltered.

Case 5, an 11-year-old boy, was first seen in 1961 with a short history of blurred vision and headaches. Congenital cyanotic heart disease, consisting of pulmonary stenosis and atrial septal defect, had been successfully treated by surgery 2 years previously, since which time the patient had been symptom-free with a normal blood oxygen level.

Examination.-He was a normally-developed boy with no neurological abnormalities. There was a symmetrical papilloedema of 2 dioptres, and the visual acuity was $6 / 6$ in both eyes. The visual fields were normal apart from enlargement of the blind spots. Lumbar puncture soon after admission to hospital showed a pressure of $200 \mathrm{~mm} . \mathrm{H}_{2} \mathrm{O}$ and a fortnight later of $250 \mathrm{~mm}$. The patient showed no electroencephalographic abnormality, and full neuroradiological investigation proved negative.

Progress.-During the 3 years following the onset of the symptoms of benign intracranial hypertension he showed persistent papilloedema of 2 dioptres. The visual fields showed a mild peripheral constriction, and the visual acuity remained unchanged.

Case 6, a 35-year-old woman, was first seen in 1962 with a short history of nausea, headaches, and diplopia. These symptoms became worse during menstruation.

Examination.-Nothing abnormal was found except a left 6th nerve palsy. Bilateral papilloedema of 2 dioptres was present, with a visual acuity of $6 / 6$ in both eyes. The visual fields showed only enlarged blind spots. Two separate lumbar punctures at an interval of a fortnight gave readings of $300 \mathrm{~mm}$. and $100 \mathrm{~mm}$. $\mathrm{H}_{2} \mathrm{O}$. Electro-encephalographic and neuroradiological examinations gave negative results.

Progress.-During the subsequent 4 years, the patient was seen at 3-monthly intervals. Papilloedema of about 2 dioptres was noted on each occasion, and the visual acuity and fields remained unaltered.

The two following cases are included despite the fact that single lumbar punctures gave values within the normal range. The clinical picture, ocular findings, and results of neuroradiological investigations are all in keeping with a diagnosis of benign intracranial hypertension, and it seems probable that, in view of the fluctuating cerebrospinal fluid pressure which is a part of the natural history of the disease, further lumbar puncture readings would at times reveal elevated values.

Case 7, an 18-year-old girl, was seen early in 1963 with headaches of recent onset, associated with blurred vision, dizziness, and nausea.

Examination.-Nothing abnormal was observed. A bilateral papilloedema of 2 dioptres was noted. The visual acuity was $6 / 6$ in both eyes, and the visual fields were normal apart from enlargement of the blind spots. Lumbar puncture showed a pressure of $150 \mathrm{~mm} \mathrm{H}_{2} \mathrm{O}$, the cerebrospinal fluid being chemically and cytologically normal. Electro-encephalography and full neuroradiological investigation revealed nothing abnormal except small ventricles.

Progress.-In 1964 small haemorrhages developed around the optic discs, and these were still present at the last follow-up late in 1966 . During the 4 years of observation, the bilateral papilloedema has remained at about 2 dioptres. From 1964 to 1966 the patient has had occasional bouts of headache and vomiting. The visual fields have remained unaltered and the visual acuity unimpaired. There were no signs of optic atrophy.

Case 8, a 16-year-old boy, developed headaches in 1963.

Examination.- Nothing abnormal was observed. A symmetrical papilloedema of 3 dioptres was noted. The visual fields were normal, apart from enlargement of the blind spots, and the visual acuity was $6 / 6$ in both eyes. A single lumbar puncture showed a pressure of $170 \mathrm{~mm}$. $\mathrm{H}_{2} \mathrm{O}$ with normal cerebrospinal fluid. Cerebral angiography revealed a severe constriction affecting the right jugular vein. Air studies were normal, 
Progress.-The patient was followed at 3-monthly intervals for 3 years. In 1964 he developed a severe defect of the left inferior nasal field, and the following year a similar defect on the right side. The papilloedema has gradually diminished, being now about 2 dioptres. Although moderate pallor of the optic discs has developed in recent months, there is no vascular constriction, the visual acuity remains unimpaired, and at the last follow-up the visual field defects were seen to have improved.

\section{Results}

Eight patients are presented, four of either sex, and ranging in age from 11 to 49 years. All presented with signs and symptoms suggesting the possibility of a cerebral tumour: five had headaches, three had nausea and vomiting, three complained of visual blurring, and one of diplopia.

Apart from the ophthalmic findings, clinical examination was largely negative. Bilateral visual acuity of $6 / 6$ was recorded in all of them at the first presentation, and no deterioration was observed during follow-up periods ranging from 3 to 6 years. Field examination revealed enlarged blind spots in every case. In one patient a mild right inferior nasal constriction appeared after 3 years, and another showed a bilateral peripheral constriction after a short interval, and this disappeared almost completely a year later. In a third case, well-marked bilateral inferior nasal defects appeared after a year, but these regressed 3 years after the onset of the illness.

Fluctuating levels of papilloedema were constant findings, and varied from 1 to 5 dioptres. In five cases, there were associated haemorrhages near the disc, and in four of these exudates were also present. Two patients developed moderate disc pallor after 3 and 6 months, but this was not accompanied by vascular constriction or deterioration of visual acuity. Lumbar puncture showed pressures fluctuating between 100 and $500 \mathrm{~mm} . \mathrm{H}_{2} \mathrm{O}$. The cerebrospinal fluid was consistently normal.

Angiography, carried out in all eight cases, revealed narrowing of the sigmoid sinus and right jugular vein in one case and of the superior sagittal sinus in another. Air studies excluded ventricular dilatation or irregularity in every patient; in two, the ventricular system was smaller than normal.

Surgical decompression performed in one case proved partially successful in controlling the intracranial pressure, rises in which were manifested by periodic bulgings of the decompression and were recorded by spinal puncture. Courses of Diamox in three cases, and repeated lumbar puncture in two, appeared ineffectual in preventing pressure rises.

All the patients remained in good general health during the follow-up period.

\section{Discussion}

The condition of benign intracranial hypertension has been the subject of regular reports in the literature since Quincke (1896) first drew attention to it over 70 years ago. It is heralded by symptoms suggestive of an intracranial space-occupying lesion. Examination reveals bilateral papilloedema of a degree that often causes considerable alarm, and this is accompanied by raised intracranial pressure. The cerebrospinal fluid is normal in all respects, and the ventricular system, when outlined by appropriate air studies, is found never to be dilated or irregular, and is often of small size. The paucity of symptoms (for the patient usually feels remarkably well) and lack of physical findings are characteristic features of the syndrome. The multiplicity of aetiological factors has caused it to masquerade under a variety of eponyms, which have sometimes sought to marry the vagaries of medical fashion with the needs of clinical classification. The names have included otitic and toxic hydro- 
cephalus, serous and aseptic meningitis, ependymitis serosa, hypertensive meningeal hydrops, meningeal hydrops, intracranial pressure of unknown cause, intracranial pressure without brain tumour, pseudo-abscess, papilloedema of indeterminate aetiology, and pseudotumour or tumour equivalent (Symonds, 1931; McAlpine, 1937; Quincke, 1896; Warrington, 1914; Sheldon, 1933; Passot, 1913; Ayala, 1925; Davidoff and Dyke, 1937; Giller and Cogan, 1952; Sahs and Hyndman, 1939; Dandy, 1937; Adson, 1924; Yaskin, Groff, and Shenkin, 1949; Warrington, 1914; Bailey, 1920). Foley (1955) coined the name benign intracranial hypertension to emphasize the eventual favourable outcome of the syndrome.

The literature briefly alluded to in our introduction reveals that in this condition papilloedema can exist for as long as 2 years without serious ultimate visual consequences, and our eight cases show a similarly benign course, in spite of disc swelling persisting for from 3 to 6 years. Even the mild atrophic changes which supervened in two cases were not followed by the marked functional sequelae usually associated with secondary optic atrophy. Similar cases were reported by Ford and Murphy (1939) and by Ray and Dunbar (1951) in which atrophic changes were not followed by deterioration of visual acuity or field. Pennybacker (1943) claimed never to have seen a case of benign intracranial hypertension with visual failure from secondary optic atrophy. Although it is difficult to explain this benign course in the presence of long-standing papilloedema, it is interesting to observe that we recorded fluctuations of the intracranial pressure between high and normal manometric levels in the six cases in which several readings were taken. This is in accord with the findings of other authors (Ford and Murphy, 1939; Pennybacker, 1943; Giller and Cogan, 1952; Bradshaw, 1956; Meadows, 1959).

Dandy (1937) suggested 30 years ago that this fluctuation might explain why these patients remain so remarkably free of general symptoms. It may also explain why the optic nerve withstands prolonged pressure so well. We do not know where these fluctuations act. The periodic falls in pressure are probably not of sufficient duration to allow the nerve head to recover completely, for papilloedema usually requires several weeks for resolution after the raised intracranial pressure is relieved. The pressure variations might well be accompanied by an intermittent improvement of local circulation in the optic nerve head. Exceptional cases of benign intracranial hypertension have been described with early development of optic atrophy and ultimate serious visual impairment. There may well be a threshold below which the intracranial hypertension must fall for adequate periods if the optic nerve is to be spared the consequences of prolonged pressure.

Many early authors, and some current ones, attribute the favourable visual outcome to timely neurosurgical intervention, usually in the form of a decompressive procedure. Most clinicians, however, currently adopt a more conservative approach. The resistance to visual deterioration of eight consecutive patients whose papilloedema persisted for 3 to 6 years supports this approach.

\section{Summary}

(1) Eight consecutive patients with benign intracranial hypertension are described, in whom papilloedema was observed for a period of 3 to 6 years.

(2) The almost entire absence of loss of function as expressed in visual acuity and visual field is emphasized, and the reason for this discussed.

(3) Support is given to a conservative approach in management.

We should like to thank Prof, I. C. Michaelson for his help with the manuscript. 


\section{REFERENCES}

Adson, A. W. (1924). Surg. Clin. N. Amer., 4, 503.

Ayala, G. (1925). Arch. ital. Otol., 36, 187 (Abstr. Rev. Laryngol., 46, 266).

BaIley, P. (1920). Arch. Neurol. Psychiat. (Chicago), 4, 401.

Bradshaw, P. (1956). J. Neurol. Neurosurg. Psychiat., 19, 28.

Cross, A. G. (1948). Trans. ophthal. Soc. U.K., 68, 181.

Dandy, W. E. (1937). Ann. Surg., 106, 492.

Davidoff, L. M., and Dyke, C. G. (1937). Amer. J. Ophthal., 20, 908.

FoleY, J. (1955). Brain, 78, 1.

FORD, F. R., and MURPHY, E. L. (1939). Bull. Johns Hopk. Hosp., 64, 369.

Giller, H., and Cogan, D. G. (1952). A.M.A. Arch Ophthal., 48, 557.

Huber, A. (1961). "Eye Symptoms in Brain Tumors", p. 112. Mosby, St. Louis.

MCAlpine, D. (1937). Brain, 60, 180.

Marr, G. W., and Chambers, R. G. (1961). Amer. J. Ophthal., 51, 605.

Meadows, S. P. (1959). Trans. ophthal. Soc. U.K., 79, 121.

PAssot, R. (1913). "Méningites et états méningés aseptiques d'origine otique.” Thèse de Paris, 1912-13. Steinheil, Paris.

Pennybacker, J. (1943). Trans. ophthal. Soc. U.K., 63, 333.

QUINCKe, H. (1896). Dtsch. Z. Nervenheilk., 9, 149.

Ray, B. S., and Dunbar, H. S. (1951). Ann. Surg., 134, 376.

SaHs, A. L., and Hyndman, O. R. (1939). Arch. Surg., 38, 428.

Sheldon, J. H. (1933). Lancet, 1, 798.

Smith, J. L. (1958). Trans. Amer. Acad. Ophthal. Otolaryng., 62, 432.

Symonds, C. P. (1931). Brain, 54, 55.

WARRINGTON, W. B. (1914). Quart. J. Med., 7, 93.

Yaskin, J. C., Groff, R. A., and Shenkin, H. A. (1949). Confin. neurol. (Basel), 9, 108. 